\title{
Quality of life issues and measurement in patients with psoriasis
}

\author{
This article was published in the following Dove Press journal: \\ Psoriasis: Targets and Therapy \\ 15 February 2012 \\ Number of times this article has been viewed
}

Xi Tan'

Steven R Feldman ${ }^{2}$

Rajesh Balkrishnan'

'Department of Clinical, Social and Administrative Sciences, College of Pharmacy, University of Michigan, Ann Arbor, MI, USA; ${ }^{2}$ Department of Dermatology, Wake Forest University School of Medicine, Winston-Salem, NC, USA
Correspondence: Rajesh Balkrishnan Department of Clinical, Social and Administrative Sciences, College of Pharmacy, University of Michigan, 428 Church Street, Ann Arbor, MI 48I09, USA

Tel +l 7347647203

Fax +l 7346158171

Email rbalkris@umich.edu
Abstract: Psoriasis is a chronic immunologic disease characterized by red papules and plaques with a silver colored scale. The impact of psoriasis on patients' overall quality of life is significant, broad, and deep, including effects on emotional wellbeing, psychological stress, self-esteem, relationship, work, social activities, financial burden, and even physical function. Although there are various measures available for assessing health-related quality of life (HRQoL) in research studies, there is no consensus on which measure is best to use in clinical practice or for research comparing different treatments. Choosing treatments based on patients' specific individual preferences, goal-orientation, and close, attentive cooperation between patients and their doctors may be an effective strategy that can be applied to improve patients' quality of life.

Keywords: treatment, health related quality of life, HRQoL

\section{Introduction}

Psoriasis is a chronic immunologic disease characterized by red papules and plaques with a silver colored scale. ${ }^{1,2}$ Psoriasis affects about $0.6 \%-4.8 \%$ of the world population and roughly $2.2 \%$ of the US population. In the US, there are about 250,000 new cases of psoriasis annually. ${ }^{3,4}$ The total direct cost of psoriasis is above US\$1 billion. ${ }^{5}$ The estimated incremental cost is US\$1500 per year, with $40 \%$ of this considered as indirect costs. ${ }^{6}$ This statistical description of psoriasis does not clearly capture the full impact of psoriasis on patients' lives.

Although psoriasis usually isn't a life-threatening condition (accepting cardiovascular and psychiatric comorbidities) and can be treated in the outpatient setting, it is a challenging and frustrating condition for patients and often for their physicians as well. Treatments are chronic and sometimes complicated. Commonly, treatment incorporates combinations of different treatment options - such as topical treatments, phototherapy, and systemic treatments - as well as different treatments for different areas of the body that are affected. ${ }^{7}$ Treatment planning is further complicated by the need to take into consideration patients' individual preferences, expectations, and quality of life (QoL). Besides the complexity of treatment, there are some other management challenges in the treatment of psoriasis such as poor adherence to treatment, risk of comorbidities, childhood psoriasis, and lifestyle modification and maintenance. ${ }^{1,8,9}$

\section{The impact of psoriasis on the lives of patients}

The impact of psoriasis on patients' overall QoL is broad and deep, including effects on emotional wellbeing, psychological stress, self-esteem, relationships, work, social 
activities, financial burden, and even physical function (particularly in patients with coexistent psoriasis arthritis). ${ }^{10-12}$ The disability caused by psoriatic is comparable to that caused by other major medical conditions. ${ }^{13}$ A 2008 National Psoriasis Foundation survey found that $71 \%$ of psoriasis patients agreed that psoriasis is a significant issue in everyday life. ${ }^{12}$ It is very common for psoriasis patients to have feelings of embarrassment, stigma, and discomfort in public because they think others may judge them by their disfigurement. Based on a recent survey, around $35 \%$ of patients avoid social activities or limit dating or intimate relationships. ${ }^{12}$

Psoriasis may reduce work productivity and is associated with a negative impact at work as measured by the Work Productivity Assessment Index. ${ }^{14}$ In more severe cases, including those with significant psoriatic arthritis (which attacks approximately a quarter of the psoriasis population), patients often experience physical dysfunction, which is associated with work disability and can cause more reduction in QoL. ${ }^{15}$ Absenteeism is another large concern for psoriasis sufferers. Due to the disease, patients with psoriasis experience more missed work days than healthy people, further contributing to indirect cost and additive economic burden. ${ }^{16}$

Psoriasis causes emotional stress, impairment of selfesteem, and mood disorders such as depression. More than half of patients (57\%) think that psoriasis negatively affects their self-esteem. ${ }^{12}$ One study reported about $50 \%$ and $30 \%$ of the psoriasis population had depression scores and anxiety scores, respectively, even higher than individuals with psychiatric problems. ${ }^{17}$ Depression is now even regarded as an important comorbidity along with psoriasis. The effects on self-esteem, emotional stress, and daily life increase the psychological burden of the disease, and may lead to depression and suicidal ideation in some cases. ${ }^{13,18} \mathrm{~A}$ study indicated that, among 127 psoriasis sufferers, 9.7\% claimed active suicidal ideation, and $5.5 \%$ stated their wish to be dead because of their psoriasis. ${ }^{19}$

\section{Review of measurements of the QoL in psoriasis patients}

Psoriasis can be measured using objective measures of the extent and severity of the skin disease, but these measures do not capture the impact of the disease on patients' lives. Objective measures such as the extent of body surface area affected or the psoriasis area severity index (PASI) are commonly used as primary outcomes in clinical trials. These objective indicators of clinical response do correlate, though not tightly, with measures of patients' health-related QoL (HRQoL). ${ }^{20}$ By capturing HRQoL data along with objective measures of skin involvement, a more complete picture of the impact of the disease and of improvements with treatment can be obtained.

Various tools can be used to assess psoriasis severity and HRQoL. These measures are classified as psoriasis-specific, skin-specific, generic, and "mixed." ${ }^{21}$ The following section illustrates each classification with some validated, commonly used instruments. The general characteristics of QoL measures in psoriasis vary (Table 1). Generally speaking, the psoriasis-specific measures are the most sensitive for identifying the impact of the disease. Generic measures are widely used in clinical trials because they permit comparisons across different diseases and help rule out the possibility that treatments that are effective for the skin are reducing patients' QoL in other dimensions. ${ }^{21}$ For assessing disease for research purposes, it is very common to use a combination of these measures, such as a specific along with a generic one. For example, the European consensus group recommended and obtained a consensus on setting up treatment goals on changes in PASI and dermatology life quality index (DLQI) scores. ${ }^{10}$ Table 2 illustrates the applications of different QoL measurements of psoriasis in clinical trials. ${ }^{34-36,38,50-52,54}$

\section{Psoriasis-specific measures}

Psoriasis disability index (PDI)

The PDI is a psoriasis-specific measure to assess patient's health-related QoL, and it is a 15-item scale. It includes areas of daily activities, personal relationship, work or school, treatment, and leisure. Even though its psychometric characteristics have been partially tested in the UK, studies show that PDI is not an optimal measure in US patients, and that psychometric properties need to be studied in the US population. ${ }^{22}$

\section{Psoriasis area and severity index (PASI)} and self-administered PASI (SAPASI)

PASI and SAPASI are important and widely used measurements for assessing the severity of psoriasis skin involvement. PASI assesses four body regions: the head (10\% of the total body surface area), the upper extremities (20\%), the trunk $(30 \%)$, and the lower extremities $(40 \%)$. The PASI score ranges from 0 to 72 , with higher score representing higher severity. ${ }^{23}$ The SAPASI is a simplified version of PASI; it uses the same criteria as the PASI but contains a silhouette of a body for patients to shade in the affected areas and three visual scales for assessing the symptoms of the regions. ${ }^{24}$ PASI and SAPASI don't directly assess the QoL but they can correspond to the measurement of the HRQoL; when 
Table I Main features of commonly used QoL measures in psoriasis

\begin{tabular}{|c|c|c|c|c|}
\hline & Physical functioning & Psychological functioning & Social functioning & Wellbeing \\
\hline \multicolumn{5}{|c|}{ Psoriasis-specific measures } \\
\hline PDI & Daily activities & - & $\begin{array}{l}\text { Personal relationships, } \\
\text { work, or school }\end{array}$ & Treatment and leisure \\
\hline PASI & Symptoms & - & - & - \\
\hline SAPASI & Symptoms & - & - & - \\
\hline PSORIQOL & Daily activities & - & $\begin{array}{l}\text { Personal relationships, } \\
\text { work, or school }\end{array}$ & Treatment and leisure \\
\hline \multicolumn{5}{|c|}{ Skin-specific measures } \\
\hline DLQI & Symptoms and daily activity & - & $\begin{array}{l}\text { Personal relationships } \\
\text { and work/school }\end{array}$ & Leisure \\
\hline DQOLS & Activity everyday and symptoms & Irritableness, despair & Social and sexual activities & $\begin{array}{l}\text { Distress and } \\
\text { embarrassment }\end{array}$ \\
\hline Skindex-29 & $\begin{array}{l}\text { Physical discomfort and physical } \\
\text { limitation }\end{array}$ & Fear, depression & Social effects & Embarrassment \\
\hline \multicolumn{5}{|c|}{ Generic QoL measures } \\
\hline SF-36 & $\begin{array}{l}\text { Role limitation because of physical } \\
\text { problems and bodily pain }\end{array}$ & Mental health & $\begin{array}{l}\text { Role limitations because } \\
\text { of emotions }\end{array}$ & General health and vitality \\
\hline EQ-5D & $\begin{array}{l}\text { Mobility, self-care, pain, } \\
\text { and discomfort }\end{array}$ & Anxiety and depression & $\begin{array}{l}\text { Usual activity (work, } \\
\text { study, family) }\end{array}$ & $\begin{array}{l}\text { Usual activity } \\
\text { (leisure activity) }\end{array}$ \\
\hline \multicolumn{5}{|c|}{ Mixed QoL measures } \\
\hline SPI & $\begin{array}{l}\text { Signs (converted PASI), interventions } \\
\text { (historic disease severity) }\end{array}$ & $\begin{array}{l}\text { Psychosocial disability } \\
\text { in day-to-day life }\end{array}$ & $\begin{array}{l}\text { Psychosocial disability } \\
\text { in day-to-day life }\end{array}$ & - \\
\hline KMPI & Physical symptoms & $\begin{array}{l}\text { Self-consciousness, } \\
\text { frustration, feeling } \\
\text { of helplessness }\end{array}$ & - & $\begin{array}{l}\text { Embarrassment, overall } \\
\text { wellbeing, capacity } \\
\text { to enjoy life }\end{array}$ \\
\hline
\end{tabular}

Adapted with permission from Bronsard V, Paul C, Prey S, et al. What are the best outcome measures for assessing quality of life in plaque type psoriasis? A systematic review of the literature. J Eur Acad Dermatol Venereol. 2010;24(Suppl 2):17-22. ${ }^{26}$

Abbreviations: DLQI, dermatology life quality index; DQOLS, dermatology quality of life scale; EQ-5D, EuroQol 5D; KMPI, Koo-Menter psoriasis instrument; PASI, psoriasis area severity index; PDI, psoriasis disability index; PSORIQoL, psoriasis index of quality of life; QoL, quality of life; SAPASI, self-administered PASI; SF-36, short form 36; SPI, Salford psoriasis index.

there is a $75 \%$ improvement in PASI $(\triangle \mathrm{PASI} \geq 75)$, good improvement in QoL is generally seen. ${ }^{20}$

\section{Psoriasis index of quality of life (PSORIQoL)}

PSORIQoL is a psoriasis-specific QoL measure which is based on the needs model and developed by qualitative interviews with psoriasis patients in three different countries in Europe. It contains 25 dichotomous items, and it's short and easy for patients to complete. PSORIQoL examines the impact on the QoL in psoriasis patients rather than assesses the symptoms or functioning. ${ }^{25}$

\section{Skin-specific measures}

\section{Dermatology life quality index (DLQI)}

The DLQI is the first specific HRQoL questionnaire for skin disease and is currently one of the most frequently used QoL questionnaires in psoriasis or other skin disease studies. It includes ten questions regarding symptoms and feelings, daily activities, leisure, work and school, personal relationships, and treatment, with each question scoring a four-point scale. Higher DLQI score indicates worse effect on QoL.
All questions are related to "the last week," and it is used in patients greater than 16 years old. The DLQI is patient friendly, well validated, and clinically interpretable, yet it may report noncomparative outcomes in different cultures, genders, and other subpopulations. ${ }^{26}$ Because it has been widely used in the past, the effects of newer treatments on DLQI can be compared with existing agents. Despite its limitations, DLQI is one of the best measures for QoL in psoriasis.

\section{Dermatology quality of life scale (DQOLS)}

The DQOLS is a self-reported skin disease specific measure, mainly focused on the impact of skin diseases on patients' psychosocial functioning and everyday activities. It consists of 17 psychosocial items and 12 activities items, which were assigned five-point scales. The psychosocial functioning section includes embarrassment, despair, irritableness, and distress, and the activity section includes everyday, summer, social, and sexual. It may facilitate comparisons among effects of different skin disorders and among different populations regardless of age, sex, socioeconomic status, and ethnicity. ${ }^{27}$ 
Table 2 The applications of different QoL measurements of psoriasis in clinical trials

\begin{tabular}{|c|c|c|c|}
\hline $\begin{array}{l}\text { QoL measurements } \\
\text { of psoriasis }\end{array}$ & Applicatio & ical trials & QoL outcomes \\
\hline PDI & Prins et $\mathrm{al}^{34}$ & $\begin{array}{l}\text { The Dutch translation of PDI was used to assess } \\
\text { QoL, and score was transformed to 0-100-point } \\
\text { to facilitate interpretation. It was applied to assess } \\
\text { treatment-induced disability, thus SIP was also } \\
\text { administered to cover the emotional domain. } \\
\text { The questionnaires were administered in } \\
\text { three groups (short contact dithranol versus }\end{array}$ & $\begin{array}{l}\text { Short contact dithranol treatment } \\
\text { and UVB phototherapy improved } \\
\text { QoL significantly }(P<0.00 \mathrm{I}) \text {. } \\
\text { Inpatients experienced reduced } \\
\text { QoL, but treatment showed } \\
\text { no significant improvement } \\
\text { in QoL directly }\end{array}$ \\
\hline
\end{tabular}

PASI $\quad$ PLUTO study
SAPASI

DLQI Langley et al ${ }^{36}$

DQOLS Feldman et al ${ }^{50}$

Skindex-29 De Korte et al ${ }^{51}$

REVEAL study ${ }^{38}$

EQ-5D at four time points (start of treatment end

of treatment, 3 months follow-up, and end of study)

PASI and SAPASI were both used to determine the severity of disease. The proportion of patients with a $50 \%$ or more improvement of the baseline PASI or SAPASI was measured as the main outcomes measure of effectiveness of treatments (home UVB phototherapy versus outpatient UVB therapy). Another outcome measured was the percentage reduction in median PASI and SAPASI scores DLQI was used to measure QoL in the ustekinumab group and the placebo group. DLQI score $>10$ was considered as large impact on QoL. DLQIs were collected at baseline, week I2, and week 24

Patients in this study were randomized to "receive alefacept for two courses, alefacept in course I and placebo in course 2, or placebo in course I and alefacept in course 2." DQOLS was used to assess the QoL "at baseline, 2 weeks after the last dose in both courses, at the beginning of course 2, and at the end of the observation period in both courses"

Skindex-29 was used to assess the QoL in the calcipotriol ointment BID group and the short-contact dithranol cream once-daily group. It was administered to the patients before treatment commenced and after the end of treatment. The questionnaire with $75 \%$ of the items completed in each scale was considered as eligible to calculate the summary score

SF-36 was used to assess HRQoL of psoriasis patients in both the adalimumab group and the placebo group. The scores were compared with US population norms at baseline and week 16. The change of 2-3 points was considered as the minimum significant difference when compared with the general US population EQ-5D was used to assess the QoL of psoriasis patients in the continuous etanercept group and the paused etanercept group. Baseline scores in both groups were measured, and the difference of scores was also measured at the end of treatment (week 54). EQ-5D utility score ranges from 0 (death) to I (perfect health), and a change of 0.05 was regarded as clinically meaningful. A change of 4-8 points in the VAS part of the EQ-5D was considered as clinically meaningful
The declines in PASI and SAPASI scores in both groups were significant $(P<0.00$ I $)$ and similar across groups $(P>0.3)$

At baseline, 54.6\% reported DLQI greater than 10. Significant improvement of DLQI scores (76.2\%) at week 12 was found in the ustekinumab group compared with placebo group $(P<0.00$ I $)$ At 12 weeks after the last dose, the mean change in DQOLS symptom scale was significantly greater in patients receiving alefacept than placebo $(-18.2$ versus - II.I, respectively, $P \leq 0.005)$

After 12 weeks of treatment, there was a significant difference in the summary score of the Skindex-29 but no significant difference in the functioning scale of the Skindex-29

The improvement in QoL associated with adalimumab was to levels that were similar to or greater than those of the general US population $(P<0.00 I)$

At baseline, mean EQ-5D utility scores were 0.65 and 0.66 in the continuous etanercept group and the paused etanercept group, respectively. Both groups at week 54 showed meaningful improvement in EQ-5D scores. The difference of EQ-5D between two groups was statistically significant but not meaningful 
Table 2 (Continued)

\begin{tabular}{|c|c|c|c|}
\hline $\begin{array}{l}\text { QoL measurements } \\
\text { of psoriasis }\end{array}$ & Applicatio & ical trials & QoL outcomes \\
\hline SPI & Wall et al ${ }^{52}$ & $\begin{array}{l}\text { SPI was used to assess the QoL before the start } \\
\text { of treatment and after the end of treatment in both } \\
\text { the calcipotriol group and the dithranol group. } \\
\text { Furthermore, the validity of SPI was assessed } \\
\text { by studying the mean changes of SPI scores correlating } \\
\text { to the researchers' assessment of patients' } \\
\text { overall clinical response }\end{array}$ & $\begin{array}{l}\text { The total mean score for SPI was } \\
\text { reduced by } 2.8 \text { in the calcipotriol } \\
\text { group }(P<0.00 \mathrm{I}) \text { and I.7 in the } \\
\text { dithranol group }(P=0.024) \\
\text { Both treatment groups have } \\
\text { significant improvement in patient's } \\
\text { QoL, with greater improvement } \\
\text { in the calcipotriol group }\end{array}$ \\
\hline KMPI & Koo et al ${ }^{54}$ & $\begin{array}{l}\text { KMPI (also known as PQOL-12) was used to assess } \\
\text { the impact of tazarotene on QoL of psoriasis patients. } \\
\text { At baseline and week I2, PQOL- } 12 \text { was administered } \\
\text { in both the tazarotene group and the placebo group. } \\
\text { The PQOL- } 12 \text { total score was calculated, with the average } \\
\text { of } 12 \text { items with scores ranging from } 0 \text { to } 10\end{array}$ & $\begin{array}{l}\text { At baseline, mean PQOL-I2 (KMPI) } \\
\text { scores of patients in the tazarotene } \\
\text { group and the placebo group were } \\
5.39 \text { and } 5.43 \text {, respectively. There } \\
\text { was a significant difference of the } \\
\text { mean changes of PQOL- } 12 \text { scores } \\
\text { (tazarotene group: }-1.63 \text {, placebo } \\
\text { group: }-0.84, P<0.000 I \text { ) }\end{array}$ \\
\hline
\end{tabular}

Abbreviations: DLQI, dermatology life quality index; DQOLS, dermatology quality of life scale; EQ-5D, EuroQol 5D; HRQoL, health-related quality of life; KMPI, KooMenter psoriasis instrument; PASI, psoriasis area severity index; PDI, psoriasis disability index; PQOL, psoriasis quality of life index; QoL, quality of life; SAPASI, selfadministered PASI; SF-36, short form 36; SIP, sickness impact profile; SPI, Salford psoriasis index; UVB, ultraviolet B; VAS, visual analogue scale.

\section{Skindex-29, Skindex- 17}

The Skindex-29 is a widely studied skin disease specific QoL measurement tool. It contains 29 questions in the areas of burden of symptoms, functioning, and emotional domains, with a five-point Likert scale; the higher the Skindex-29 score the worse effect on QoL. The Skindex-17 is a Rasch-reduced version of Skindex-29, and it has two independent scores utilized in measuring skin disease related QOL. Although they are not as widely used as the DLQI, these measures have good psychometric properties and cross-cultural validation..$^{26,28}$

\section{Generic QoL measures}

\section{Short form 36 (SF-36)}

The SF-36 is a self-reported, 36-item, generic health survey which can be used across age groups ( $\geq 18$ years old), multiple disease states, and different treatment options. ${ }^{26}$ It contains eight sections, including vitality, physical functioning, bodily pain, general health perceptions, physical role functioning, emotional role functioning, social role functioning, and mental health. Each scale can be scored from 0 to 100, and the higher the score the higher the QoL. ${ }^{21}$ It is well validated, clinically interpretable, and culturally and linguistically adaptable. ${ }^{28}$ The limitation of SF-36 is that it mainly focuses on physical functioning in areas that may not be affected by skin disease. Therefore, it's often recommended to use SF-36 with a skin-specific or psoriasis-specific tool when measuring QoL in psoriasistreatment studies.

\section{EuroQol 5D (EQ-5D)}

The EQ-5D is a self-reported generic preference-based instrument developed by the EuroQol Group to assess general health status. It is easy and quick for patients to complete and appropriate for mail surveys, in-clinic use, and face-to-face interviews. ${ }^{29}$ It can be used across countries. It consists of areas of mobility, self care, usual activity, pain/discomfort, and anxiety/depression. Using a formula which is based on the valuation of EQ-5D health states from general population samples, EQ-5D health state date can be converted to a summary index..$^{29}$ The second part of EQ-5D is a vertical $20 \mathrm{~cm}$ visual analogue scale with the end points labeled best imaginable health state at the top and worst imaginable health state at the bottom. ${ }^{29}$ This part is designed only for research on valuing health..$^{29}$ The disadvantage of EQ-5D in use of psoriasis assessment is that it is a measurement tool of general health status rather than HRQoL. In addition, it is not that sensitive when used in a specific disease. As a result, using another skin-specific measure or psoriasis-specific measure along with EQ-5D in assessing the QoL in psoriasis sufferers is suggested.

\section{Mixed QoL measures}

\section{Salford psoriasis index (SPI)}

The SPI is designed to assess psoriasis severity but does so from a holistic perspective; it also takes psychosocial disability into consideration. It is derived from the similar concept as the TNM (tumor/nodes/metastasis) cancer staging classification and has a measure for three categories: signs, 
psychosocial disability, and interventions. It has high reliability and validity and is sensitive to change. The signs are scores converted from PASI. The psychosocial disability is a visual analogue scale which assesses the impact of psoriasis on the patient's everyday life. The interventions are extra points added because of historical disease severity. ${ }^{30}$

\section{Koo-Menter psoriasis instrument (KMPI)}

The KMPI is an important instrument for therapeutic decision making from both the patient's and physician's perspectives and is also a good record for the third-party payers. ${ }^{31}$ It is divided into two parts, completed by patient and physician, respectively. Although the questions are easy to understand and answer, the questionnaire is very thorough in content, which not only contains HRQoL index but also a psoriasis quality of life index (PQOL-12) and other measurements. ${ }^{32}$ The questions are mainly related to "the past month."

Choosing the appropriate measure of QoL in psoriasis patients can be based on: ${ }^{30}$ (1) the reason for use (for example, if the measurement is used to compare the effect on psoriasis with other nonskin diseases, a generic QoL measure seems to be more appropriate; if the purpose is to compare the effect on psoriasis with another skin disease, a skin disease specific measure may be superior due to better sensitivity and specificity), (2) validity and reliability of the measure, (3) time context of the measure (the frequency of using a measure may depend on the time context of the questionnaire; some measures ask questions related to the last week, while some relate to the past month), (4) settings (whether in mail survey, busy clinic setting, or face-to-face interview, we can choose either short simplified form or a detailed complicated version depending on the situation), and (5) language and culture equivalence. ${ }^{30}$

In all, no single tool is ideal for all QoL measurement needs, each having its own advantages and limitations.

\section{Summary of current therapies available and impact on QoL}

There are many currently available treatment options for psoriasis (Table 3). The array of treatment is very broad, encompassing topical medications, physical treatments (phototherapy), and different types of systemic treatments. A host of potential different combinations of these can be made. Choosing among these many treatments is based on the severity, comorbidities, patient's preference, efficacy, and patient-specific clinical response to the treatment. ${ }^{1}$ Treatment decisions are all the more complicated because the treatments themselves may adversely affect QoL; for some patients, use of prescribed treatments may be worse than the disease (a recipe that almost guarantees poor adherence).

For mild to moderate plaque psoriasis, topical therapy is generally recommended. Topical corticosteroids, emollients, and vitamin D analogs are first-line treatments. There are additional topical therapies, including coal tar, tazarotene (topical retinoids), and anthralin. To get better clinical response while minimizing adverse effects, combinations of topicals may be prescribed, and localized phototherapy is another option. ${ }^{1}$ Although combinations of topicals could significantly improve patients' QoL, ${ }^{33}$ all of these topical approaches are limited by the time consuming, and sometimes messy or smelly nature of topical treatment.

Table 3 Current available treatments for psoriasis

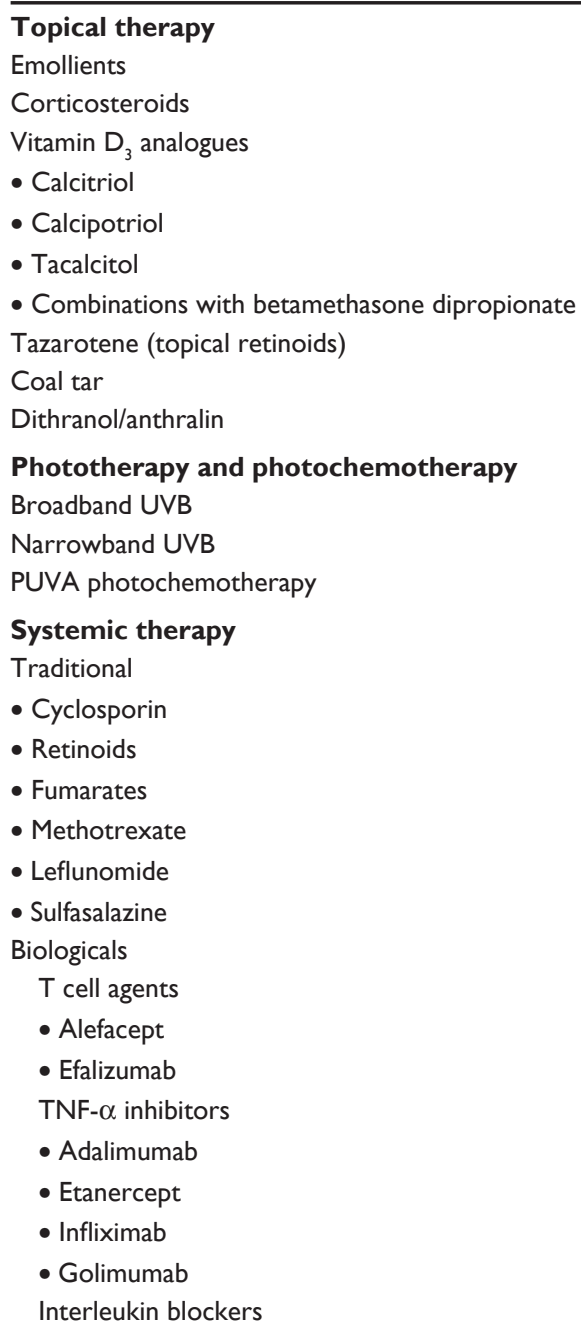

Adapted from Menter AM, Griffiths CEM. Current and future management of psoriasis. Lancet. 2007;370:272-284. ${ }^{7}$

Abbreviations: PUVA, psoralen and ultraviolet A; TNF- $\alpha$, tumor necrosis factor $\alpha$; UVB, ultraviolet $B$. 
For moderate-to-severe plaque psoriasis, phototherapy is recommended to be initiated first if feasible. ${ }^{1}$ Topical therapies may be administered as adjunct therapy, especially for recalcitrant lesions. The most effective wavelength of ultraviolet (UV) for psoriasis is in the range of $311-313 \mathrm{~nm}$ (narrowband UVB). Phototherapy is effective at clearing psoriasis and may result in long remissions; phototherapy is also among the safest treatment options for long-term control of severe psoriasis. ${ }^{21}$ Oral retinoids are often combined with UVB or UVA phototherapy because of synergies. ${ }^{7}$ Prins et al showed short contact dithranol treatment could improve QoL significantly (Sickness Impact Profile 68, $P<0.05$; PDI, $P<0.001)$ and similar results showed in the UVB phototherapy treatment group. ${ }^{34}$ Additionally, the PLUTO study showed patients' QoL increased equally in office-based phototherapy and home phototherapy. ${ }^{35}$ However, office-based phototherapy is not convenient or affordable for some patients, and the time consuming nature of this approach adds to the burden of the disease. Home phototherapy may make phototherapy more accessible for some patients and further resultes in greater patients' satisfaction. ${ }^{35}$

Systemic agents are recommended for more extensive or refractory cases, termed moderate-to-severe psoriasis, along with psoriatic arthritis. ${ }^{1}$ Systemic agents can include photochemotherapy, oral agents such as retinoids, methotrexate, cyclosporine, and biological immune modifying agents such as alefacept, adalimumab, etanercept, infliximab, and ustekinumab. ${ }^{1}$ These biological immune modifying agents consistently showed significant improvement in QoL in psoriasis patients. ${ }^{36-45}$ Although biological agents are effective for psoriasis, the cost and potential for long-term side effects are limitations of biological agents used for psoriasis. Nevertheless, biologic treatments have been a tremendous advance in the treatment of psoriasis, offering patients with severe disease much better tolerated options, ones that have a large effect on improving patients' QoL.

The efficacy of current therapeutic treatment options for psoriasis is often examined or compared by using the results obtained with QoL measurement tools in clinical trials (Table 4). ${ }^{33-45,51-53,55-57}$ Comparing the efficacy of different treatments is complex, however, due to the use of different outcome measurements. None of the available QoL measures are perfect for both clinical practice and research purposes. Even if a new QoL measure which is specific to psoriasis, adequate in psychometrics, cross-culturally equivalent, and can offer comparative outcomes in different clinical studies were found, it would still have the disadvantage of not being comparable to the large amount of data already collected in past clinical trials with existing QoL measures.

\section{Conclusion and future directions}

Drug development for psoriasis is an exciting area of research in dermatology, with future directions in the areas of genetic determinants, targets of potential drugs, new approaches on treatment management, and new concepts or measurement tools related to $\mathrm{QoL}$ in psoriasis patients.

Psoriasis has considerable genetic determinants. The association of several candidate genes with psoriasis has been corroborated ${ }^{46}$ Performing genome-wide association scans in psoriasis to further define the genetic determinants of psoriasis, to identify new targets, and to provide pharmacogenomic information for choosing treatment is a promising area. ${ }^{46}$

Based on our evolving understanding of the immunopathogenesis of psoriasis, exciting targets for new drug development in psoriasis are cell signaling molecules, including IL-12/23, IL-10, IL17, IL-20, and IL-23. Monoclonal antibody targeting IL-12/23 such as briakinumab and ustekinumab are effective in moderate to severe patients. Targeting the interruption of intracellular signaling is another future direction of new drug development. The potential drugs include the inhibitors of JAK kinases, phosphodiesterase 4, and protein kinase C. ${ }^{1}$ The development of small molecular oral treatments for psoriasis is expected to help address the QoL limitations of injectable treatment.

Nanotechnology applications are being developed in the management of skin disease and are one of the promising directions which can improve pharmaceutical delivery at targeted sites and reduce side effects. New nanotechnologybased formulations such as nanoparticles are expected to be beneficial for topical agents applied in psoriasis. For example, nanoencapsulated retinoids can lead to less irritation since they have more stable properties and controlled, sustained release. ${ }^{47}$ Encapsulated topical steroids that are currently under development could also be very useful in the management of psoriasis. They could to a large extent reduce the risk of the systematic side effects of topical steroids by making the drug build up in the epidermis and not penetrate the dermis. ${ }^{47}$

The European consensus group is working on developing and implementing the new approach of "targeted-treatment, early intervention and the use of treatment goals" in treating psoriasis. ${ }^{10}$ Goal-oriented treatment management has been successfully applied to other chronic diseases such as diabetes and rheumatoid arthritis in the last decade. It may assist and guide in treating psoriasis and improve health outcomes. This treatment management method involves a treatment plan, 
Table 4 Clinical trials of psoriasis treatments, quality of life measures utilized, and outcomes

\begin{tabular}{|c|c|c|c|}
\hline Clinical trial & Treatment & QoL measures & Outcomes \\
\hline Langley et al ${ }^{36}$ & $\begin{array}{l}\text { Ustekinumab } 45 \mathrm{mg} \text {, } \\
90 \mathrm{mg} \text { versus placebo }\end{array}$ & HADS, DLQI & $\begin{array}{l}\text { The use of ustekinumab showed significant } \\
\text { improvements in symptoms of anxiety, } \\
\text { depression, and QoL }\end{array}$ \\
\hline Menter et $\mathrm{a}^{37}$ & $\begin{array}{l}\text { Adalimumab } 40 \mathrm{mg} \text { every } \\
\text { other week versus placebo }\end{array}$ & $\begin{array}{l}\text { ZDS, PASI, DLQI, } \\
\text { SF-36 }\end{array}$ & $\begin{array}{l}\text { Adalimumab significantly reduced symptoms, } \\
\text { depression and improved QoL compared with } \\
\text { the placebo group }\end{array}$ \\
\hline REVEAL study ${ }^{38}$ & $\begin{array}{l}\text { Adalimumab } 80 \mathrm{mg} \text { versus } \\
\text { placebo }\end{array}$ & SF-36 & $\begin{array}{l}\text { The improvement in QoL associated with } \\
\text { adalimumab was to levels that were similar to or } \\
\text { greater than those of the general US population }\end{array}$ \\
\hline $\begin{array}{l}\text { REVEAL study } \\
\text { subanalysis }^{39}\end{array}$ & $\begin{array}{l}\text { Adalimumab } 80 \mathrm{mg} \text { versus } \\
\text { placebo }\end{array}$ & $\begin{array}{l}\text { PASI, DLQI, SF-36, } \\
\text { WPAI }\end{array}$ & $\begin{array}{l}\text { Comorbidities were associated with additionally } \\
\text { impaired QoL and work productivity in psoriasis } \\
\text { patients. Adalimumab can significantly improve } \\
\text { QoL in patients with psoriasis }\end{array}$ \\
\hline CLEAR trial ${ }^{40}$ & $\begin{array}{l}\text { Efalizumab I mg/kg/wk } \\
\text { for } 12 \text { weeks versus placebo }\end{array}$ & $\begin{array}{l}\text { SF-36, DLQI, PSA, } \\
\text { VAS, PGPA }\end{array}$ & $\begin{array}{l}\text { Efalizumab group improved QoL significantly as } \\
\text { compared with the placebo group }(P<0.00 \text { I })\end{array}$ \\
\hline CRYSTEL study ${ }^{41}$ & $\begin{array}{l}\text { Continuous etanercept } 25 \mathrm{mg} \\
\text { BIW over } 54 \text { weeks versus } \\
\text { paused etanercept } 50 \mathrm{mg} \\
\text { BIW } \leq 12 \text { weeks }\end{array}$ & $\begin{array}{l}\text { DLQI, EQ-5D, HADS, } \\
\text { SF-36, vitality scale }\end{array}$ & $\begin{array}{l}\text { Both groups significantly improved QoL, but no } \\
\text { significant difference between these two groups }\end{array}$ \\
\hline Krueger et $\mathrm{al}^{42}$ & $\begin{array}{l}\text { Etanercept } 50 \mathrm{mg} \text { twice weekly } \\
\text { ( } 50 \mathrm{mg} \text { per week during } \\
\text { the initial I } 2 \text { weeks) } \\
\text { versus placebo }\end{array}$ & DLQI, SF-36, PGPA & $\begin{array}{l}\text { Significant improvement in etanercept group as } \\
\text { measured by DLQI, SF-36, and PGPA }\end{array}$ \\
\hline $\begin{array}{l}\text { Van de Kerkhof } \\
\text { et } \mathrm{al}^{43}\end{array}$ & Alefacept & PASI, DLQI & $\begin{array}{l}\text { The improvement of QoL by treating with } \\
\text { alefacept in patients who were not candidates for } \\
\text { traditional systemic therapies or phototherapy } \\
\text { was similar to the overall alefacept-treated } \\
\text { population }(P=0.00 \mathrm{I})\end{array}$ \\
\hline Feldman et $\mathrm{a}^{44}$ & $\begin{array}{l}\text { Infliximab } 3 \mathrm{mg} / \mathrm{kg}, 5 \mathrm{mg} / \mathrm{kg} \text {, } \\
\text { placebo }\end{array}$ & PASI, DLQI, SF-36 & $\begin{array}{l}\text { Regardless of baseline patient characteristics } \\
\text { or comorbidities, infliximab treatment can } \\
\text { consistently improve QoL. Among the groups, } \\
\text { infliximab } 5 \mathrm{mg} / \mathrm{kg} \text { improved QoL and PASI } \\
\text { scores most over } 50 \text { weeks }\end{array}$ \\
\hline Feldman et $\mathrm{a}^{45}$ & $\begin{array}{l}\text { IV infusion of } 3 \mathrm{mg} / \mathrm{kg} \text { infliximab, } \\
5 \mathrm{mg} / \mathrm{kg} \text { infliximab, or placebo }\end{array}$ & DLQI & $\begin{array}{l}\text { Infliximab } 3 \mathrm{mg} / \mathrm{kg} \text { and } 5 \mathrm{mg} / \mathrm{kg} \text { groups } \\
\text { significantly improved DLQI scores by } 84 \% \text { and } \\
91 \% \text {, respectively, and compared with } 0 \% \text { in the } \\
\text { placebo group }(P<0.00 \mathrm{I})\end{array}$ \\
\hline PLUTO study ${ }^{35}$ & $\begin{array}{l}\text { Home UVB phototherapy } \\
\text { versus outpatient UVB } \\
\text { phototherapy }\end{array}$ & PASI, SAPASI, SF-36 & $\begin{array}{l}\text { The declines in PASI and SAPASI scores in both } \\
\text { groups were significant }(P<0.00 \mathrm{I}) \text { and similar } \\
\text { across groups }(P>0.3) \text {. QoL increased equally } \\
\text { in both treatments }\end{array}$ \\
\hline De Korte et $\mathrm{a}^{51}$ & $\begin{array}{l}\text { Calcipotriol ointment BID } \\
\text { versus short-contact dithranol } \\
\text { cream once daily }\end{array}$ & Skindex-29, SF-36 & $\begin{array}{l}\text { No significant differences in QoL between these } \\
\text { two groups }\end{array}$ \\
\hline Prins et $\mathrm{al}^{34}$ & $\begin{array}{l}\text { Short contact dithranol versus } \\
\text { UVB phototherapy versus } \\
\text { inpatient dithranol }\end{array}$ & $\begin{array}{l}\text { Dutch short form } \\
\text { of the SIP; PDI }\end{array}$ & $\begin{array}{l}\text { Short contact dithranol treatment and UVB } \\
\text { phototherapy improved QoL significantly } \\
\text { Inpatients experienced reduced QoL, but } \\
\text { treatment showed no significant improvement in } \\
\text { QoL directly }\end{array}$ \\
\hline Gottlieb et $\mathrm{al}^{53}$ & $\begin{array}{l}\text { Clobetasol propionate } \\
\text { foam } 0.05 \%\end{array}$ & PGA & $\begin{array}{l}\text { Clobestasol propionate foam } 0.05 \% \text { had greater } \\
\text { improvement in } \mathrm{Q} \text { L as compared with other } \\
\text { topical therapies reported by patients }\end{array}$ \\
\hline $\begin{array}{l}\text { Heydendael } \\
\text { et al }{ }^{55}\end{array}$ & $\begin{array}{l}\text { Methotrexate (initial dose, } \\
15 \mathrm{mg} / \mathrm{wk} \text { ) versus cyclosporine } \\
\text { (initial dose, } 3 \mathrm{mg} / \mathrm{kg} / \mathrm{d} \text { ) }\end{array}$ & PASI, PGA & No significant difference in QoL \\
\hline Salek et al ${ }^{56}$ & Cyclosporin & DLQI, PASI & $\begin{array}{l}\text { Intermittent short courses significantly improved } \\
\text { QoL and decreased the severity of disease and itch }\end{array}$ \\
\hline
\end{tabular}


Table 4 (Continued)

\begin{tabular}{|c|c|c|c|}
\hline Clinical trial & Treatment & QoL measures & Outcomes \\
\hline Alora-Palli et a ${ }^{57}$ & $\begin{array}{l}\text { Coal tar solution }(\mathrm{LCD}) \\
\text { I5\% versus calcipotriol } \\
\text { cream } 0.005 \%\end{array}$ & PASI, PGA & $\begin{array}{l}\text { LCD solution was more effective and as well } \\
\text { tolerated and cosmetically acceptable as the } \\
\text { calcipotriol cream }\end{array}$ \\
\hline Van de Kerkhof ${ }^{33}$ & $\begin{array}{l}\text { Topical calcipotriol }(50 \mathrm{mg} / \mathrm{g})+ \\
\text { betamethasone dipropionate } \\
(0.5 \mathrm{mg} / \mathrm{g}) \text { versus calcipotriol } \\
\text { monotherapy }\end{array}$ & PDI, EQ-5D, VAS & $\begin{array}{l}\text { Once-daily use of the combination product is } \\
\text { superior to calcipotriol BID in improving QoL }\end{array}$ \\
\hline Wall et al ${ }^{52}$ & $\begin{array}{l}\text { Calcipotriol ointment }(50 \mathrm{mg} / \mathrm{g} \text { ) } \\
\text { BID versus dithrocream } \\
\text { (short-contact dithranol) } 0.1 \%-2.0 \%\end{array}$ & PDI, SIP & $\begin{array}{l}\text { Both treatment groups have significant } \\
\text { improvement in patient's QoL, with greater } \\
\text { improvement in calcipotriol group }\end{array}$ \\
\hline
\end{tabular}

Abbreviations: DLQI, dermatology life quality index; EQ-5D, EuroQol 5D; HADS, hospital anxiety and depression scale; LCD, liquor carbonis detergens; PASI, psoriasis area severity index; PDI, psoriasis disability index; PGA, physician global assessment; PGPA, patient's global psoriasis assessment; PSA, psoriasis symptom assessment; QoL, quality of life; SF-36, short form 36; SIP, sickness impact profile; UVB, ultraviolet B; VAS, visual analogue scale; WPAI, work productivity assessment index; ZDS, Zung depression scale.

clinical response monitoring, and appropriate adjustment of the treatment if there is a gap between the clinical response and goal. To implement this approach and accomplish the best outcome, strategies for overcoming the barriers, recruiting a multidiscipline health care provider team to collaborate, and most importantly, getting patients actively involved in this process are needed.

A novel concept called "Cumulative Life Course Impairment (CLCI) is helpful for understanding the burden of psoriasis." ${ }^{48,49}$ The CLCI concept is that impairment of QoL in psoriasis patients is cumulative and can lead to failure to achieve a "full life potential." CLCI may be used as a surrogate marker to assess the cumulative impact of psoriasis and biopsychosocial outcomes over patients' life course. ${ }^{48,49}$ Not only will CLCI take the cumulative effect on QoL into consideration, it will also extend the effect to comorbidities as well. In this way, we may have a potential gold standard measure of the cumulative effect on psoriasis patients' QoL. It may be helpful to learn the rationale for the earlier treatment strategies in psoriasis.

Psoriasis is an incurable chronic immune disorder that affects patients' QoL significantly and often dramatically. Although there are various measures available for assessing QoL in research studies, there is no consensus on which one is best to use in clinical practice or for research comparing different treatments. Choosing treatments based on patients' specific individual preferences, goal-orientation, and close, attentive cooperation between patients and their doctors may be an effective strategy that can be applied to improve patients' QoL.

\section{Disclosures}

Dr Feldman has received research, speaking, and/or consulting support from Abbott, Amgen, Astellas, Janssen, Galderma Laboratories, GSK/Stiefel, Novartis, National Biological
Corporation, and the National Psoriasis Foundation. Feldman is founder and majority owner of the DrScore.com patient satisfaction Web site. ${ }^{58}$

Dr Balkrishnan has received research and/or consulting support from Galderma Laboratories and Leo Pharmaceuticals.

\section{References}

1. Feldman SR. Epidemiology, pathophysiology, clinical manifestations, and diagnosis of psoriasis. In: Basow DS, editor. UpToDate. Waltham, MA: UpToDate Inc; 2011.

2. Naldi L. Epidemiology of psoriasis. Curr Drug Targets Inflamm Allergy. 2004;3:121-128.

3. Lebwohl M. Psoriasis. Lancet. 2003;361:1197-1204.

4. Stern RS, Nijsten T, Feldman SR, Margolis DJ, Rolstad T. Psoriasis is common, carries a substantial burden even when not extensive, and is associated with widespread treatment dissatisfaction. $J$ Investig Dermatol Symp Proc. 2004;9:136-139.

5. The Lewin Group, Inc. The burden of skin diseases. 2004. Available from: http://www.sidnet.org/pdfs/Burden $\% 20$ of $\% 20$ Skin $\% 20$ Diseases\%202004.pdf. Accessed September 28, 2011.

6. Fowler JF, Duh MS, Rovba L, et al. The impact of psoriasis on health care costs and patient work loss. J Am Acad Dermatol. 2008;59(5):772-780.

7. Menter AM, Griffiths CEM. Current and future management of psoriasis. Lancet. 2007;370:272-284.

8. Storm A, Andersen SE, Benfeldt E, Serup J. One in 3 prescriptions are never redeemed: primary nonadherence in an outpatient clinic. $J \mathrm{Am}$ Acad Dermatol. 2008;59:27-33.

9. Coates LC, Jonckheere CL, Molin S, Mease PJ, Ritchlin CT. Summary of the International Federation of Psoriasis Associations (IFPA) Meeting: a report from the GRAPPA 2009 Annual Meeting. J Rheumatol. 2011;38:530-539.

10. Mrowietz U, Kragballe K, Nast A, Reich K. Strategies for improving the quality of care in psoriasis with the use of treatment goals a report on an implementation meeting. J Eur Acad Dermatol Venereol. 2011;25(Suppl 3):1-13.

11. Husted JA, Tom BD, Farewell VT, Schentag CT, Gladman DD. A longitudinal study of the effect of disease activity and clinical damage on physical function over the course of psoriatic arthritis: does the effect change over time? Arthritis Rheum. 2007;56:840-849.

12. National Psoriasis Foundation 2008 Survey Snapshot. Available from: http://www.psoriasis.org/document.doc?id=193. Accessed September 27, 2011. 
13. Rapp SR, Feldman SR, Exum ML, Fleischer AB, Reboussin DM. Psoriasis causes as much disability as other major medical diseases. J Am Acad Dermatol. 1999;41:401-407.

14. Pearce DJ, Singh S, Balkrishnan R, Kulkarni A, Fleischer AB, Feldman SR. The negative impact of psoriasis on the workplace. $J$ Dermatolog Treat. 2006;17:24-28.

15. Wallenius M, Skomsvoll JF, Koldingsnes W, et al. Work disability and health-related quality of life in males and females with psoriatic arthritis. Ann Rheum Dis. 2009;68:685-689.

16. Schmitt J, Ford DE. Understanding the relationship between objective disease severity, psoriatic symptoms, illness-related stress, health-related quality of life and depressive symptoms in patients with psoriasis - a structural equations modeling approach. Gen Hosp Psychiatry. 2007;29:134-140.

17. Evers AW, Lu Y, Duller P, van der Valk PG, Kraaimaat FW, van de Kerkhof PC. Common burden of chronic skin diseases? Contributors to psychological distress in adults with psoriasis and atopic dermatitis. Br J Dermatol. 2005; 152:1275-1281.

18. Esposito M, Saraceno R, Giunta A, Maccarone M, Chimenti S. An Italian study on psoriasis and depression. Dermatology. 2006;212:123-127.

19. Gupta MA, Schork NJ, Gupta AK, Kirkby S, Ellis CN. Suicidal ideation in psoriasis. Int J Dermatol. 1993;32:188-190.

20. Revicki DA, Willian MK, Menter A, Saurat J-H, Harnam N, Kaul M. Relationship between clinical response to therapy and health-related quality of life outcomes in patients with moderate to severe plaque psoriasis. Dermatology. 2008;216:260-270.

21. Bhosle MJ, Kulkarni A, Feldman SR, Balkrishnan R. Quality of life in patients with psoriasis. Health Qual Life Outcomes. 2006;4:35.

22. Nijsten T, Whalley D, Gelfand J, Margolis D, Mckenna SP, Stern RS. The psychometric properties of the psoriasis disability index in United States patients. J Invest Dermatol. 2005;125:665-672.

23. Ashcroft DM, Wan Po AL, Williams HC, Griffiths CE. Clinical measures of disease severity and outcome in psoriasis: a critical appraisal of their quality. Br J Dermatol. 1999;141:185-191.

24. Fleischer AB, Rapp SR, Reboussin DM, Vanarthos JC, Feldman SR. Patient measurement of psoriasis disease severity with a structured instrument. J Invest Dermatol. 1994;102:967-969.

25. McKenna SP, Cook SA, Whalley D, et al. Development of the PSORIQoL, a psoriasis-specific measure of quality of life designed for use in clinical practice and trials. Br J Dermatol. 2003;149(2):323-331.

26. Bronsard V, Paul C, Prey S, et al. What are the best outcome measures for assessing quality of life in plaque type psoriasis? A systematic review of the literature. J Eur Acad Dermatol Venereol. 2010;24(Suppl 2): $17-22$.

27. Morgan M, McCreedy R, Simpson J, Hay RJ. Dermatology quality of life scales - a measure of the impact of skin diseases. Br J Dermatol. 1997;136(2):202-206.

28. Nijsten TE, Sampogna F, Chren MM, Abeni DD. Testing and reducing Skindex-29 using Rasch analysis: Skindex-17. J Invest Dermatol. 2006;126:1244-1250.

29. What is EQ-5D. Valuation of EQ-5D. Available from: http://www. euroqol.org/eq-5d/what-is-eq-5d.html. Accessed October 1, 2011.

30. Lewis VJ, Finlay AY. A critical review of Quality-of-Life Scales for Psoriasis. Dermatol Clin. 2005;23(4):707-716.

31. Feldman SR, Koo JY, Menter A, Bagel J. Decision points for the initiation of systemic treatment for psoriasis. J Am Acad Dermatol. 2005;53:101-107.

32. Van Voorhees A, Feldman SR, Koo JYM, Lebwohl MG, Menter A. The psoriasis and psoriatic arthritis pocket guide: treatment algorithms and management options. National Psoriasis Foundation. Available from: http://www.psoriasis.org/document.doc?id=354. Accessed October 1, 2011.

33. Van de Kerkhof P. The impact of a two-compound product containing calcipotriol and betamethasone dipropionate (Daivobet/Dovobet) on the quality of life in patients with psoriasis vulgaris: a randomized controlled trial. Br J Dermatol. 2004;151:663-668.
34. Prins M, Krabbe PF, Swinkels QO, de Boo T, vande Kerkhof PC, van der Valk PG. The effect of treatment on quality of life in psoriasis patients. Acta Derm Venereol. 2005;85:304-310.

35. Koek MB, Buskens E, van Weelden H, Steegmans PH, Bruijnzeel-Koomen CA, Sigurdsson V. Home versus outpatient ultraviolet $\mathrm{B}$ phototherapy for mild to severe psoriasis: pragmatic multicentre randomized controlled non-inferiority trial (PLUTO study). BMJ. 2009;338:b1542.

36. Langley RG, Feldman SR, Han C, et al. Ustekinumab significantly improves symptoms of anxiety, depression, and skin-related quality of life in patients with moderate-to-severe psoriasis: results from a randomized, double-blind, placebo-controlled Phase III trial. $J$ Am Acad Dermatol. 2010;63:457-465.

37. Menter A, Augustin M, Signorovitch J, et al. The effect of adalimumab on reducing depression symptoms in patients with moderate to severe psoriasis: a randomized clinical trial. $J$ Am Acad Dermatol. 2010;62:812-818.

38. Revicki DA, Menter A, Feldman S, Kimel M, Harnam N, Willian MK. Adalimumab improves health-related quality of life in patients with moderate to severe plaque psoriasis compared with the United States general population norms: results from a randomized, controlled Phase III study. Health Qual Life Outcomes. 2008;6:75.

39. Kimball AB, Bensimon AG, Guerin A, et al. Efficacy and safety of Adalimumab among patients with moderate to severe psoriasis with co-morbidities: subanalysis of results from a randomized, doubleblind, placebo-controlled, Phase III trials. Am J Clin Dermatol. 2011;12(1):51-62.

40. Ortonne JP, Shear N, Shumack S, Henninger E. Impact of efalizumab on patient-reported outcomes in high-need psoriasis patients: results of the international, randomized, placebo controlled Phase III Clinical Experience Acquired with Raptiva (CLEAR) trial. BMC Dermatol. 2005;5:13.

41. Dauden E, Griffiths CEM, Ortonne JP, et al. Improvements in patientreported outcomes in moderate-to-severe psoriasis patients receiving continuous or paused etanercept treatment over 54 weeks: the CRYSTEL study. J Eur Acad Dermatol Venereol. 2009;23:1374-1382.

42. Krueger GG, Langley RG, Finlay AY, et al. Patient-reported outcomes of psoriasis improvement with etanercept therapy: results of a randomized Phase III trial. Br J Dermatol. 2005;153:1192-1199.

43. Van de Kerkhof P, Griffiths CE, Christophers E, Lebwohl M, Krueger GG. Alefacept in the treatment of psoriasis in patients for whom conventional therapies are inadequate. Dermatology. 2005;211:256-263.

44. Feldman SR, Gottileb AB, Bala M, et al. Infliximab improves health-related quality of life in the presence of comorbidities among patients with moderate-to-severe psoriasis. $\mathrm{Br} J$ Dermatol. 2008;159:704-710.

45. Feldman SR, Gordon KB, Bala M, et al. Infliximab treatment results in significant improvement in the quality of life of patients with severe psoriasis: a double-blind placebo-controlled trial. Br J Dermatol. 2005;152:954-960.

46. Duffin KC, Chandran V, Gladman DD, Krueger GG, Elder JT, Rahman P. Genetics of psoriasis and psoriatic arthritis: update and future direction. J Rheumatol. 2008;35(7):1449-1453.

47. Nasir A. Nanodermatology: a bright glimpse just beyond the horizon Part I. Available from: http://www.skintherapyletter.com/2010/15.8/1. html. Accessed December 15, 2011.

48. Kimball AB, Gieler U, Linder D, Sampoqna F, Warren RB, Augustin M. Psoriasis: is the impairment to a patient's life cumulative? J Eur Acad Dermatol Venereol. 2010;24(9):989-1004.

49. Kimball A, Gieler U, Linder D, et al. Re. Major life-changing decisions and cumulative life course impairment. J Eur Acad Dermatol Venereol. 2011;25:246.

50. Feldman SR, Menter A, Koo JY. Improved health-related quality of life following a randomized controlled trial of alefacept treatment in patients with chronic plaque psoriasis. Br J Dermatol. 2004;150:317-326. 
51. De Korte J, Van Der Valk PGM, Sprangers MAG, et al. A comparison of twice-daily calcipotriol ointment with once-daily short-contact dithranol cream therapy: quality-of-life outcomes of a randomized controlled trial of supervised treatment of psoriasis in a day-care setting. Br J Dermatol. 2008;158:375-381.

52. Wall AR, Poyner TF, Menday AP. A comparison of treatment with dithranol and calcipotriol on the clinical severity and quality of life in patients with psoriasis. Br J Dermatol. 1998;139:1005-1011.

53. Gottlieb AB, Ford RO, Spellman MC. The efficacy and tolerability of clobetasol propionate foam $0.05 \%$ in the treatment of mild to moderate plaque-type psoriasis of nonscalp regions. J Cutan Med Surg. 2003;7:185-192.

54. Koo JY, Kowalski J, Guenther L, Walker P. Quality of life effect of oral tazarotene in patients with moderate to severe psoriasis as measured by the 12-item psoriasis quality of life questionnaire (PQOL-12). Presented at the 62nd Annual Meeting of the American Academy of Dermatology; February 6-11, 2004; Washington, DC.
55. Heydendael VM, Spuls PI, Opmeer BC, et al. Methotrexate versus cyclosporine in moderate-to-severe chronic plaque psoriasis. $N$ Engl J Med. 2003;349:658-665.

56. Salek MS, Finlay AY, Lewis JJ, Sumner MI. Quality of life and clinical outcome in psoriasis patients using intermittent cyclosporine (Neoral). Qual Life Res. 2004;13:91-95.

57. Alora-Palli MB, Perkins AC, Van Cott A, Kimball AB. Efficacy and tolerability of a cosmetically acceptable coal tar solution in the treatment of moderate plaque psoriasis: a controlled comparison with calcipotriene (calcipotriol) cream. Am J Clin Dermatol. 2010;11(4):275-283.

58. DrScore.com [homepage on the Internet]. Available from: http://www. drscore.com. Accessed January 8, 2012.

Psoriasis: Targets and Therapy

\section{Publish your work in this journal}

Psoriasis: Targets and Therapy is international, peer-reviewed, open access journal focusing on psoriasis, nail psoriasis, psoriatic arthritis and related conditions, identification of therapeutic targets and the optimal use of integrated treatment interventions to achieve improved outcomes

and quality of life. Visit http://www.dovepress.com/testimonials.php to read real quotes from published authors. 